\title{
ENTRE O ESPORTE E A ARTE CIRCENSE: ENTREVISTA COM MARIANA MAEKAWA
}

Entrevista realizada com a artista e profissional de Educação Física Mariana Maekawa

Entrevistador: Marco Antonio Coelho Bortoleto, Universidade Estadual de Campinas UNICAMP, Campinas, São Paulo - Brasil

\section{Apresentação}

Egressa da Faculdade de Educação Física da Unicamp em 2007, durante vários anos Mariana Maekawa fez parte do espetáculo Love da companhia canadense Cirque du Soleil, em Las Vegas. Porém, entre essas duas experiências inúmeras coisas aconteceram muitas das quais, podem ajudar a outras pessoas da área no momento de pensar sua carreira profissional e/ou acadêmica. Vamos a nossa conversa com essa talentosa e dedicada atleta-artista.

Mariana, conte-nos, por favor, como aconteceu seu envolvimento com o esporte, em particular com a ginástica artística?

Tudo começou quando eu tinha aproximadamente 9 anos de idade. Busquei um clube do bairro onde eu morava, na época, interessada em praticar acrobacias. Sempre adorei ficar de ponta-cabeça e fui atraída por atletas que vendiam camisetas na quitanda de meus pais. Pratiquei Ginástica Artística por aproximadamente 10 anos, tendo a oportunidade de participar em distintas competições, como jogos regionais, jogos abertos, campeonatos paulista e brasileiro, copa São Paulo, entre outras. Participei também da World Gymnaestrada, grande evento mundial de ginástica geral realizado no ano de $1995 \mathrm{em}$ Berlim (Alemanha). A maior parte dessa experiência foi quando treinava no Clube Campineiro de Regatas e Natação, embora eu também tenha treinado por um ano na academia Yashi, localizada em São Paulo.

Você poderia fazer uma breve apresentação de sua formação profissional no âmbito da Educação Física e como o circo foi se incorporando à sua vida?

Entrei na FEF-Unicamp no ano de 2003, e o circo surgiu na minha vida praticamente na mesma época. Um ano antes de ingressar na universidade, graduandos da FEF-Unicamp Conexões: revista da Faculdade de Educação Física da UNICAMP, Campinas, v. 13, n. especial, p. 230-235, maio 2015. ISSN: 1983-9030 
me convidaram para fazer parte de um grupo acrobático (Kikapoo), cuja especialidade era o banquini ${ }^{1}$. No ano seguinte, ingressei no curso de Educação Física e fui mergulhando cada vez mais no universo das atividades circenses. Logo comecei a participar de um grupo de malabaristas (LosCircoLos) e fazia aulas de aéreos com o professor circense Alex Brede na escola Cia do Circo, em Barão Geraldo. Entre aulas na FEF e treinos de circo, os anos foram passando e o conhecimento universitário e as experiências com apresentações e performances iam se misturando. O desafio de cumprir a carga horária da faculdade, dar aulas de ginástica artística e circo e trabalhar como artista tornaram esses 4 anos da minha vida muito intensos, ricos e divertidos! Tudo isso me motivou a escrever meu TCC sobre o tema (MAEKAWA, 2006).

\section{Conte-nos um pouco sobre sua experiência circense antes do Cirque du Soleil e como a FEF-Unicamp contribuiu com ela?}

Minha experiência circense antes de ir para o Cirque du Soleil pode ser resumida na participação nos grupos Kikapoo e LosCircoLos (PAOLIELLO et al., 2014) bem como nos treinos com o professor Alex Brede, em que desenvolvi um número de trapézio fixo com o parceiro Rodrigo Mallet Duprat. Os trabalhos circenses nesse período variavam entre eventos, desenvolvimento de pequenos espetáculos e números com os grupos. Participei também da Unicirco, circo mantido pela empresa Marcos Frota Produções, onde trabalhei pela primeira vez sob uma lona de circo.

Certamente a FEF contribui na minha formação como artista, principalmente por permitir-me usar o espaço físico e a estrutura do ginásio. Fui muito importante ter um espaço para treinos, ensaios, utilizar a aparelhagem e consequentemente conhecer pessoas da área que também frequentavam o ginásio da FEF. Além disso, os conhecimentos gerais (anatomia, cinesiologia, treinamento, etc.) colaboraram, uma vez que pude conhecer na teoria aquilo que meu corpo realiza quando estou treinando, aprendendo movimentos ou realizando minha preparação física.

\footnotetext{
${ }^{1}$ Especialidade circense em que acrobatas denominados "base" lançam a partir de uma base constituída pelas mãos entrecruzadas um ou mais companheiros, conhecidos como "volantes" ou "top", que realizam acrobacias no ar regressando.

Conexões: revista da Faculdade de Educação Física da UNICAMP, Campinas, v. 13, n. especial, p. 230-235, maio 2015. ISSN: 1983-9030
} 
E sobre a experiência em Las Vegas, quais foram as principais dificuldades e desafios? E quais as grandes conquistas e aprendizagens?

A chegada a Las Vegas foi em janeiro de 2007. Nem pude ir à colação de grau da Unicamp, pois logo após ser aprovada em uma audição do Cirque du Soleil em São Paulo fui convidada a trabalhar em um dos espetáculos nos Estados Unidos. Minha mãe foi quem pegou meu diploma para mim.

As dificuldades foram muitas, principalmente com o idioma, dores no corpo em função da rotina de treinos, entender uma nova cultura, estar longe da família e amigos. Os desafios de um novo trabalho, de aprender os números que apresentaria rapidamente também se fizeram presentes. Mas as conquistas também vieram. Foram mais de 3.000 apresentações do espetáculo LOVE nesse período. Pude aprender novas técnicas em distintos aparelhos circenses, dominar o inglês e até mesmo um pouco de espanhol, estar em contato com excelentes artistas, participar de grandes eventos e de um filme com a produção do Cirque du Soleil. Fiz, inclusive, curso de Health Coach, área na qual tenho hoje grande interesse. E o principal: consegui fazer amizades com pessoas de diversos lugares do mundo.

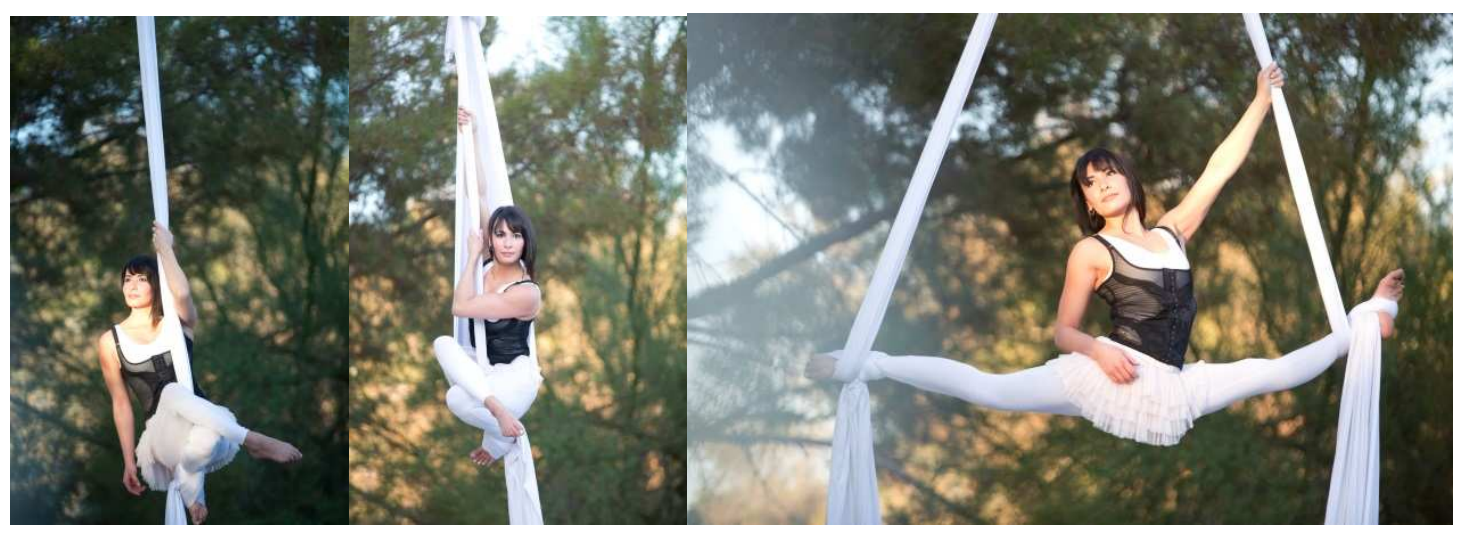

Figura 1 - Prática do tecido circense.

Fonte - Acervo pessoal da entrevistada.

Sua formação em Educação Física contribuiu de algum modo para sua experiência como artista circense profissional? Há alguma relação que mereça destaque?

Acredito que a experiência com a universidade enriqueceu minhas vivências tanto no conhecimento teórico quanto nas aulas práticas. A oportunidade de conhecer pessoas com

Conexões: revista da Faculdade de Educação Física da UNICAMP, Campinas, v. 13, n. especial, p. 230-235, maio 2015. ISSN: 1983-9030 
diferentes interesses também é relevante, uma vez que me permitiu ampliar as expectativas. A troca com as pessoas e o dinamismo da universidade é muito enriquecedor. Em relação à Educação Física, as matérias científicas contribuíram para eu entender o funcionamento do corpo; já as matérias práticas me permitiram experimentar momentos de criações e a realização de pequenas performances que também influenciaram no contato com a parte mais artística que a Educação Física também engloba.

Durante minha graduação conheci diversas pessoas que frequentavam a FEF-UNICAMP para praticar atividades circenses, como o pessoal do Kikapoo, e por isso destaco aqui a necessidade de haver esse espaço de interação entre as pessoas para que haja crescimento, troca.

\section{Qual, na sua opinião, poderiam futuras contribuições entre a Educação Física e o} Circo?

Acredito que os estudos científicos, seja em pesquisas de mestrado, seja em doutorados, já têm colaborado para ampliar nossos conhecimentos sobre diversos temas relacionados ao circo. O trabalho desenvolvido pelo Grupo de pesquisa CIRCUS e a disciplina "Atividades circenses e Educação Física", por exemplo, podem ser destacados (BORTOLETO; CELANTE, 2011). Vejo como necessário continuar estudando e apoiando o circo na universidade. Ter um espaço físico onde a Educação Física e o Circo se misturam é de absoluta importância para que haja a relação de aproximação entre essas duas áreas, permitindo a formação de novos artistas e ou educadores que possam atuar nesse segmento. Quando essas duas áreas se encontram, percebo o enriquecimento do circo principalmente no que diz respeito ao cuidado e preparação do corpo. O alto rendimento exige treinamento e planejamento, e a Educação Física nos oferece bons fundamentos nesse assunto. Também precisamos desenvolver temas e conteúdos que nos ajudem a pensar e viver o aspecto artístico e sensível da arte, contribuindo assim para uma formação mais expressiva do corpo.

\section{Após anos trabalhando no Cirque du Soleil, como está sendo sua volta ao Brasil? Quais são os planos para o futuro?}

Conexões: revista da Faculdade de Educação Física da UNICAMP, Campinas, v. 13, n. especial, p. 230-235, maio 2015. ISSN: 1983-9030 
A volta para o Brasil é carregada de alegria, novidades, incertezas, medo, mas com a certeza de que para haver crescimento é necessário transformar. O meu retorno vem dessa necessidade de transformação a fim de me tornar uma artista feliz! Os desafios hoje são outros. Meu profissionalismo e a busca em criar e me expressar por meio da arte e do corpo me levam a ter imenso prazer na carreira de artista. Sobre os planos para o futuro é difícil dizer, pois essa é uma profissão com muitas surpresas e incertezas. Hoje estou de volta à minha terra natal, e reconstruir meu dia a dia por aqui vem sendo bem prazeroso!

No começo de 2014, fui convidada pela Cia Irmãos Sabatino para participar da criação e circulação de um novo espetáculo. Composta pelos irmãos Martin e André Sabatino (este também ex-aluno da FEF), passei por um período de muita criatividade com esse grupo e já começamos as apresentações e participações em festivais, como o Festival Paulista de Circo.

\section{Por fim, você gostaria de deixar alguma mensagem para nossos alunos e também para todos os profissionais que leem a Revista Conexões, especialmente no que concerne à construção da carreira profissional?}

Acredito que investir naquilo que lhe dá prazer, não ter medo de mudar seus planos, aproveitar ao máximo o local e as pessoas que estão ao seu redor com certeza o levarão a um caminho de sucesso. Sucesso para mim é sinônimo de ser feliz! A carreira profissional é consequência da realização das buscas pessoais. Conecte-se consigo mesmo e tenha atitude, e não poupe esforços para buscar aquilo que o faz feliz!

\section{REFERÊNCIAS}

BORTOLETO, M. A. C.; CELANTE, A. R. O ensino das atividades circenses no curso de Educação Física: experiências na universidade pública e privada. In: PEREIRA, E. M. A.; CELANI, G.; GRASSI-KASSISSE, D. M. (Org.). Inovações curriculares: experiências no ensino superior. Campinas: FE/UNICAMP, 2011, v. 1. p. 178-190.

MAEKAWA, M. R. Arte, circo e Educação Física. Trabalho de Conclusão de Curso (Graduação) - Faculdade de Educação Física, Universidade Estadual de Campinas, Campinas, 2006.

Conexões: revista da Faculdade de Educação Física da UNICAMP, Campinas, v. 13, n. especial, p. 230-235, maio 2015. ISSN: 1983-9030 
PAOLIELlO, E. P. et al. Grupo Ginástico Unicamp 25 anos. Campinas: Ed. da Unicamp, 2014.

UNIVERSIDADE ESTADUAL DE CAMPINAS (UNICAMP). 21 dez. 2006. Disponível em: http://www.unicamp.br/unicamp/noticias/cirque-du-soleil-seleciona-alunos-da-fef-edo-grupo-ginástico.

UNIVERSIDADE ESTADUAL DE CAMPINAS (UNICAMP). 04 jan. 2007. Disponível em: http://www.unicamp.br/unicamp/noticias/em-las-vegas-estréia-de-mariana-no-cirquedu-soleil. 